\title{
The Use of Methyl Ethyl Ketone in Nitric Acid Leaching Processes for Enhancement of Ag Recovery from Used X-ray Films
}

\author{
Hyeonji Jo ${ }^{1,2}$, Kyoungkeun Yoo ${ }^{1, *}$, Soo-kyung Kim ${ }^{2}$ and Richard Diaz Alorro ${ }^{3}$ \\ ${ }^{1}$ Department of Energy \& Resources Engineering, Korea Maritime and Ocean University, Busan 49112, South Korea \\ ${ }^{2}$ Mineral Resources Division, Korea Institute of Geoscience and Mineral Resources (KIGAM), Daejeon 34132, South Korea \\ ${ }^{3}$ Department of Mining Engineering and Metallurgical Engineering, Western Australian School of Mines (WASM), \\ Curtin University, Kalgoorlie, WA 6430, Australia
}

A feasibility study was carried out to improve conventional recycling processes of used X-ray film, where silver was recovered mainly by concentrated nitric acid leaching. In the X-ray film, an emulsion layer containing silver is attached to polyester film base, and the enhancement of Ag leaching was expected by separating the emulsion layer from the polyester film base using methyl ethyl ketone (MEK), because the separation could increase the contact surface between nitric acid and $\mathrm{Ag}$ in the emulsion layer. First, the separation behaviors using MEK were investigated and the separation efficiencies of the emulsion layer increased with increasing temperature but decreasing film size and pulp density. The separation efficiency increased to $100 \%$ in MEK solution within 3 min under the following conditions; temperature $50^{\circ} \mathrm{C}$; setting agitation speed $400 \mathrm{rpm}$; pulp density $50 \mathrm{~g} / \mathrm{L}$; film size $1 \times 1 \mathrm{~cm}$. In the followed nitric acid leaching test, the leaching result using the separated emulsion layer showed higher leaching efficiency than that using the unseparated X-ray film. Second, the effect of adding MEK to nitric acid leaching on the leaching efficiency of Ag was investigated by considering the amount of MEK added and temperature as experiment factors. The leaching efficiency of Ag increased with increasing the amount of MEK to 5\%, but further addition of MEK to $7 \%$ rather reduce the leaching efficiency. With $5 \%$ of MEK addition, the leaching efficiency of $\mathrm{Ag}$ increased up to $95.9 \%$ in $120 \mathrm{~min}$ at $50^{\circ} \mathrm{C}$ whereas it increased and then decreased to $2.7 \%$ in the test at $70^{\circ} \mathrm{C}$ due to the formation of $\mathrm{AgCl}$. These results indicate that the leaching efficiency of $\mathrm{Ag}$ could be enhanced using MEK in the nitric acid process for the recovery of Ag from the used X-ray film. [doi:10.2320/matertrans.M2017278]

(Received September 11, 2017; Accepted November 6, 2017; Published March 16, 2018)

Keywords: methyl ethyl ketone (MEK), used X-ray film, silver recovery, nitric acid leaching

\section{Introduction}

Silver (Ag) has been used in various fields such as photography, radiography, electronics, photonics, electricity, catalysts, batteries, jewelry, silverware, dental materials, biomedicine, medicines and infectious diseases, and its demand has increased consistently. ${ }^{1)}$ About $18 \%$ of silver demand has been supplied by recovering silver from photographic wastes. ${ }^{2,3)}$ Silver, especially silver nanoparticle, has been reported to be very harmful to the human body when released into the environment. ${ }^{4,5)}$ Therefore, the recycling of photographic wastes has been required to recover silver and prevent its release in the environment.

Figure 1 shows that the cross sectional structure of X-ray film. The emulsion layer is mainly composed of gelatin matrix, in which silver components are dispersed as silver halide such as $\mathrm{AgBr}, \mathrm{AgCl}$, and $\mathrm{AgI},{ }^{6,7)}$ and it has been reported that $\mathrm{X}$-ray films contain around $1.5 \%$ of silver. ${ }^{2,3,8)}$ Burning processes had been used to concentrate the silver but the processes have disadvantages such as the loss of film base. ${ }^{2)}$ Hydrometallurgical processes have been recognized as an alternative.

Various leaching agents such as cyanide, ${ }^{9)}$ nitric acid, ${ }^{10,11)}$ and thiosulfate ${ }^{12)}$ were investigated to dissolve silver from used X-ray film. As shown in Fig. 1, because the emulsion layer containing silver components is attached to the film base, only one side of the emulsion layer is exposed to the leaching agents, which could reduce leaching efficiencies of silver. It was expected that the leaching efficiency of silver could be enhanced by separating the emulsion layer. $2,3,6,8,13-15)$ Some separation processes were developed

*Corresponding author, E-mail: kyoo@kmou.ac.kr

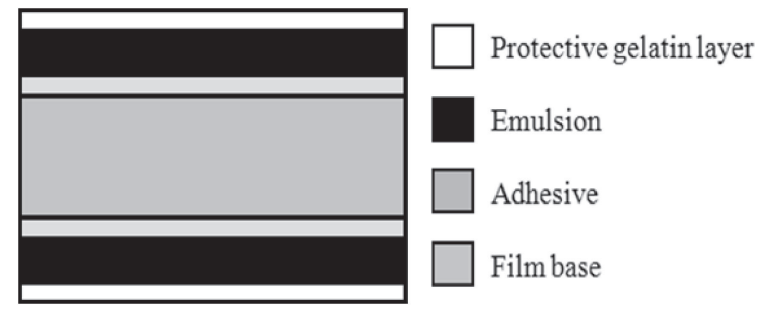

Fig. 1 Cross sectional structure of X-ray film.

using oxalic acid, ${ }^{6,13)}$ sodium hydroxide, ${ }^{2,14)}$ biologicallyproduced protease. , $^{3,8,15)}$

Methyl ethyl ketone (MEK) has been well known as its relatively low cost and toxicity. ${ }^{16)}$ It has been reported that this organic solvent could swell some resins, where swollen resin behaves like solution or suspension. ${ }^{17)}$ Also MEK has been famous for cleaner or thinner for polyester because MEK could change the surface property of polyester used as film base in X-ray film. ${ }^{18)}$ Thus, it was expected that addition of MEK could separate the emulsion layer from the film base. Therefore, two kinds of experiment sets were investigated; the separating behaviors of the emulsion layer in MEK solvent and the effects of MEK addition on the leaching of $\mathrm{X}$-ray film in nitric acid solution. The effects of various experimental factors such as temperature, agitation speed, film size, and pulp density were examined in the tests.

\section{Experiments}

\subsection{Materials}

Used X-ray films were collected from a recycling company in Korea, and they were used for inspection during shipbuilding. The content of $\mathrm{Ag}$ was measured to be 

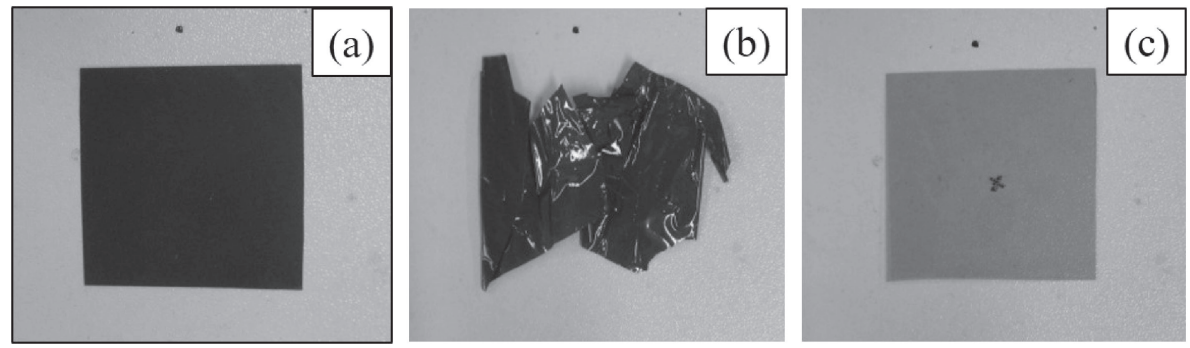

Fig. 2 The photos of (a) used X-ray film, (b) separated emulsion layer, and (c) separated polyester film base.

$22800 \mathrm{mg} / \mathrm{kg}$, which was analyzed by an analytical company (Yucheon Tech. Co.). The used X-ray films were cut to the proper sizes $(1 \times 1 \mathrm{~cm}, 2 \times 2 \mathrm{~cm}, 4 \times 4 \mathrm{~cm})$ before experiments. Nitric acid (Junsei Chemical Co., Ltd., Japan) and methyl ethyl ketone (Junsei Chemical Co., Ltd., Japan) used in this study are of reagent grade.

\subsection{Separation test of emulsion layer}

Separation tests were performed in a $250 \mathrm{~cm}^{3}$ waterjacketed reactor, which was connected to a heating bath circulator (WCB 6, Daihan Scientific Co., Ltd., Korea), to maintain temperature of solution. The reactor was charged with $100 \mathrm{~cm}^{3}$ of MEK and capped with silicone stopper. After increasing the temperature of MEK to $30-60^{\circ} \mathrm{C}$, the prepared $\mathrm{X}$-ray films were placed into the reactor. During the test, the solution was stirred with magnetic bar at up to $400 \mathrm{rpm}$, where magnetic stirring system was chosen because the emulsion layer, after separating, floated and interrupted blade-type stirring. Separation efficiency was calculated at designated time interval with the following equation.

$$
\text { Separation efficiency }(\%)=\mathrm{Ns} / \mathrm{Nt} \times 100
$$

where Ns indicates the number of X-ray film pieces separated and $\mathrm{Nt}$ is the whole number of X-ray film pieces.

\subsection{Nitric acid leaching and analysis procedures}

Nitric acid leaching was conducted in a $500 \mathrm{~cm}^{3}$ threenecked Pyrex glass reactor using a heating mantle to maintain temperature. The reactor was fitted with a stirrer and a reflux condenser to avoid solution loss at high temperatures. Leach solution was prepared by adding MEK to $1 \mathrm{M} \mathrm{HNO}_{3}$. A $200 \mathrm{~cm}^{3}$ of leach solution was placed in the reactor and allowed to reach thermal equilibrium at desired temperatures $\left(40-70^{\circ} \mathrm{C}\right)$. The used X-ray film pieces were added to the solutions and agitation speeds were set at $400 \mathrm{rpm}$. During the tests, $2 \mathrm{~cm}^{3}$ of the solution sample was withdrawn periodically at a desired time interval. The solution was filtered with a $0.45-\mu \mathrm{m}$ membrane filter and then diluted with $5 \% \mathrm{HNO}_{3}$ solution. The concentration of $\mathrm{Ag}$ was measured with AA7000 atomic absorption spectrometry (Shimadzu Co. Ltd., Japan), and leach residue was analyzed with MESA 50 X-ray fluorescence (XRF) analyzer (Horiba Ltd., Japan). Leaching efficiency of $\mathrm{Ag}$ was obtained from the following equation;

$$
\text { Leaching efficiency }(\%)=\mathrm{Ms} /(\mathrm{Ms}+\mathrm{Mr}) \times 100
$$

where Ms and Mr represent the mass of silver in solution and in leach residue, respectively. The Ag concentration in the leach residue was measured after digesting with concentrated nitric acid, and, during the leaching test, the Ag contents in the leach residue was obtained as follows; after converting the Ag concentration measured in the next sampling, added the converted Ag content to that in final leach residue.

\section{Results and Discussions}

The effects of agitation speed (100 rpm to $400 \mathrm{rpm}$ ) on the separation of emulsion film from the used X-ray film were examined in MEK solution at $50^{\circ} \mathrm{C}$ with $20 \mathrm{~g} / \mathrm{L}$ pulp density and $1 \times 1 \mathrm{~cm}$ film size. The emulsion layers were separated completely from the film bases within 3 min regardless of the agitation speeds in the range between $100 \mathrm{rpm}$ and $400 \mathrm{rpm}$ (data not shown). As shown in Fig. 2, the used X-ray film piece (Fig. 2(a)) was separated into wrinkled-shape emulsion layer (Fig. 2(b)) and polyester film base (Fig. 2(c)). Since the polyester base is blue, it was easily distinguished from the black X-ray film, and the separation efficiencies could be calculated. It has been found that MEK could swell some resins ${ }^{17)}$ or change the surface energy of polyester. ${ }^{18)}$ The swelling of the emulsion layer was not observed in the test. Gelatin is a main component in the adhesive layer as well as in the emulsion layer although minor components are not disclosed. Therefore, since generally gelatin and polyester are not swollen by MEK, the separation of the emulsion layer from the film base would be caused by the change of surface energy of polyester due to MEK. Although the separation was completed rapidly at all agitation speeds used in this study, since the film pieces were observed to occasionally interfere with the agitation, the agitation speed was fixed at $400 \mathrm{rpm}$ to ensure a stable agitation force in all subsequent separation tests.

The effects of temperature on the separation were investigated in MEK solution at $400 \mathrm{rpm}$ with $20 \mathrm{~g} / \mathrm{L}$ pulp density and $1 \times 1 \mathrm{~cm}$ film size. The separation tests were conducted in the temperature range of $30^{\circ} \mathrm{C}$ to $60^{\circ} \mathrm{C}$. Since the boiling point of MEK is $79.6^{\circ} \mathrm{C}$, the temperature range was set to avoid the evaporation of MEK. As shown in Fig. 3, a faster separation is achieved at higher temperatures. The separation was completed within $3 \mathrm{~min}$ at 50 and $60^{\circ} \mathrm{C}$, whereas it took $40 \mathrm{~min}$ at $30^{\circ} \mathrm{C}$. Therefore, the temperature of $50^{\circ} \mathrm{C}$ was selected in all subsequent separation tests. The effects of pulp density were examined in MEK solution at $400 \mathrm{rpm}$ and $50^{\circ} \mathrm{C}$ with $20-80 \mathrm{~g} / \mathrm{L}$ pulp density and $1 \times 1 \mathrm{~cm}$ film size. As shown in Fig. 4, the separation was achieved completely within $3 \mathrm{~min}$ at $20 \mathrm{~g} / \mathrm{L}$ or $50 \mathrm{~g} / \mathrm{L}$ pulp density, but, in the test at $80 \mathrm{~g} / \mathrm{L}$ pulp density, the separation 


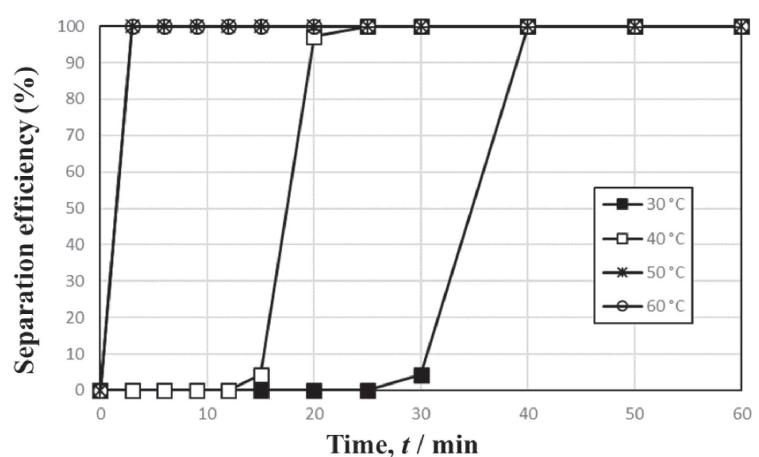

Fig. 3 The effects of temperature on the separation of emulsion layer in MEK solution at $400 \mathrm{rpm}$ with $20 \mathrm{~g} / \mathrm{L}$ pulp density and $1 \times 1 \mathrm{~cm}$ film size.

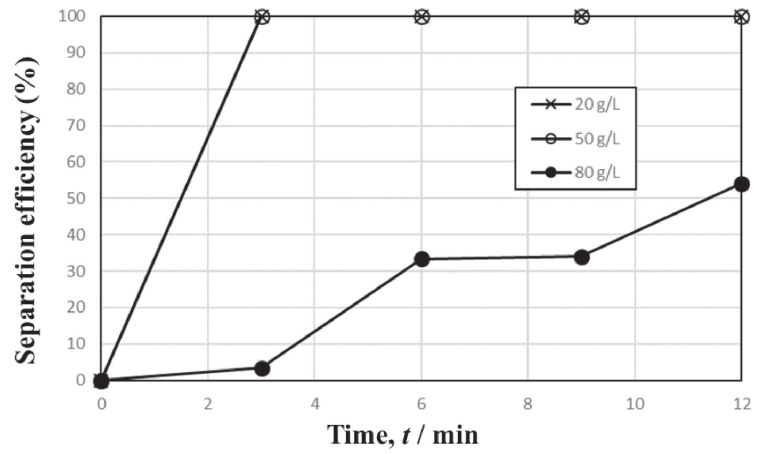

Fig. 4 The effects of pulp density on the separation of emulsion layer in MEK solution at $400 \mathrm{rpm}$ and $50^{\circ} \mathrm{C}$ with $20-80 \mathrm{~g} / \mathrm{L}$ pulp density and $1 \times 1 \mathrm{~cm}$ film size.

efficiency was $54.1 \%$ at $12 \mathrm{~min}$. In this study, a magnetic stirring system was employed because the separated emulsion layer floats and interrupt the stirring of blade-type stirrer. In the separation test with $80 \mathrm{~g} / \mathrm{L}$ pulp density, the stirring was interrupted by the film samples, which could cause the low separation efficiency, and the test did not last more than 12 min. Further research will be required on favorable and proper stirring methods.

The polyester film bases are also important valuables, and thus, generally in the conventional recycling processes, used $\mathrm{X}$-ray films are cut into an appropriate size (mostly $2-4 \mathrm{~cm}$ length) for subsequent polyester recycling before recovering Ag from X-ray films. Therefore, the effects of film size on the separation were investigated in MEK solution at $400 \mathrm{rpm}$ and $50^{\circ} \mathrm{C}$ with $20 \mathrm{~g} / \mathrm{L}$ pulp density. Three sizes $(1 \times 1 \mathrm{~cm}$, $2 \times 2 \mathrm{~cm}, 4 \times 4 \mathrm{~cm})$ of X-ray film were prepared, and the results were given in Fig. 5. The separation was completed within $3 \mathrm{~min}$ in the test with $1 \times 1 \mathrm{~cm}$ size and within $6 \mathrm{~min}$ in the tests with $2 \times 2 \mathrm{~cm}$ and $4 \times 4 \mathrm{~cm}$ sizes. The solvents penetrate more easily between the layers when the film has the smaller the area.

A comparative leaching test was carried out in $1 \mathrm{M}$ nitric acid solution at $50^{\circ} \mathrm{C}$ and $400 \mathrm{rpm}$ with $10 \mathrm{~g} / \mathrm{L}$ pulp density. The leaching behavior of silver during nitric acid leaching was well-established because the effects of agitation speed, pulp density, nitric acid concentration, and temperature were reported in the conventional studies. ${ }^{19-22)}$ Since at least one mole of nitric acid was required to leach the silver, ${ }^{20-22)} 1 \mathrm{M}$ of nitric acid concentration was selected in this leaching test.

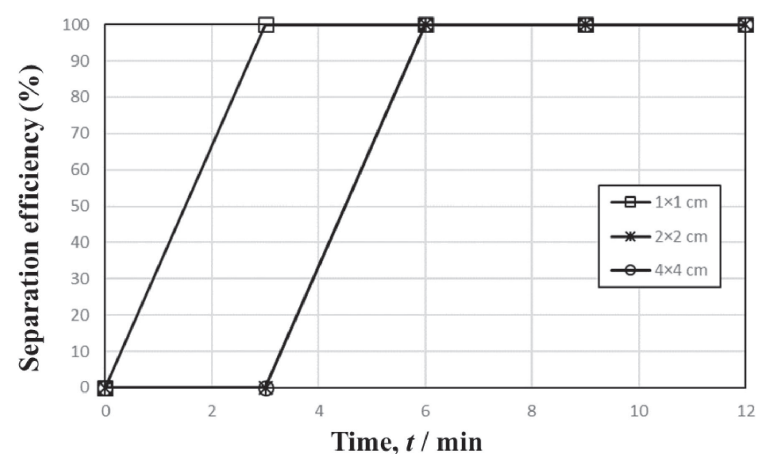

Fig. 5 The effects of film size on the separation of emulsion layer in MEK solution at $400 \mathrm{rpm}$ and $50^{\circ} \mathrm{C}$ with $20 \mathrm{~g} / \mathrm{L}$ pulp density.

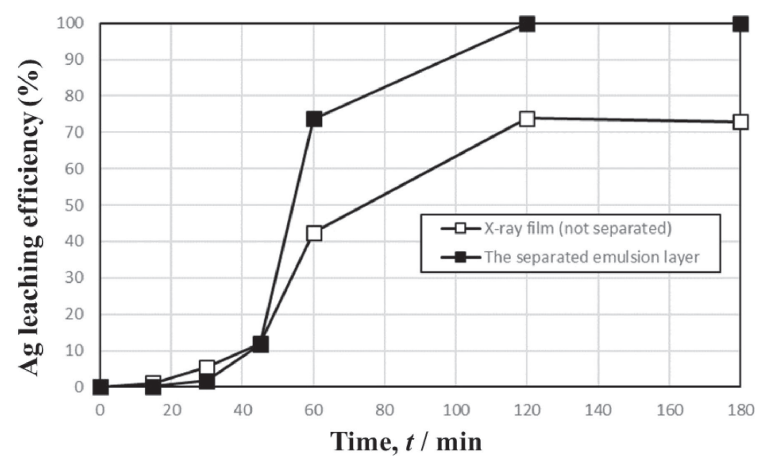

Fig. 6 The leaching efficiencies of Ag from the separated emulsion layer (solid) and X-ray film (not separated) (open) in $1 \mathrm{M}$ nitric acid solution at $50^{\circ} \mathrm{C}$ and $400 \mathrm{rpm}$ with $10 \mathrm{~g} / \mathrm{L}$ pulp density.

In this study, it was expected that the leaching efficiency of Ag could be enhanced by separating the emulsion layer from the film base, which could expose the both sides of emulsion layer to nitric acid. Therefore, for comparison, two kinds of sample were prepared; one is the X-ray film piece itself $(1 \times 1 \mathrm{~cm}$ size) as shown in Fig. 2(a), and the other is the separated emulsion layer as shown in Fig. 2(b). The separated emulsion layer pieces were collected from the preliminary separation test with $10 \mathrm{~g} / \mathrm{L}$ pulp density and $1 \times 1 \mathrm{~cm}$ X-ray film size. Figure 6 shows that the leaching results; the leaching efficiency of $\mathrm{Ag}$ increased to almost $100 \%(232 \mathrm{mg} / \mathrm{L})$ within $120 \mathrm{~min}$ using the separated emulsion layer, while, in the leaching test with the X-ray film, the efficiency was $73.0 \%$ at $180 \mathrm{~min}$. In the case of the leaching test with the separated emulsion layer, the color of the solution turned black within $30 \mathrm{~min}$ and then became a clear solution within $120 \mathrm{~min}$. However, in that with the $\mathrm{X}$-ray film, the emulsion layer was observed like black sludge on the surface of film base as a leach residue. This result indicates that the separation of the emulsion layer in advance is more preferable for the leaching of Ag from X-ray film.

Although the separation process using MEK showed beneficial effects of $\mathrm{Ag}$ recovery, it is not easy to add new process to the conventional process. In this study, a feasibility of adding MEK to nitric acid leaching process was investigated. As mentioned above, since the leaching behaviors of $\mathrm{Ag}$ in nitric acid solution were wellestablished, ${ }^{19-22)}$ only the effects of MEK addition to nitric acid solution and temperature were investigated in this study. 


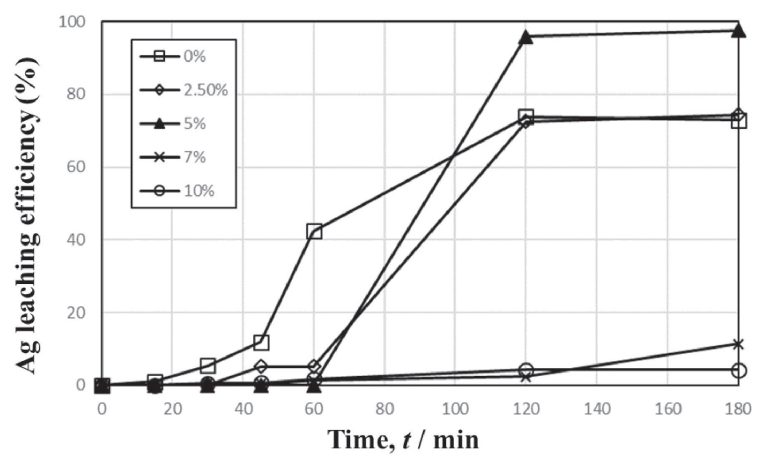

Fig. 7 The effect of MEK amount added on the leaching efficiency of Ag in $1 \mathrm{M}$ nitric acid solution at $400 \mathrm{rpm}$ and $50^{\circ} \mathrm{C}$ with $10 \mathrm{~g} / \mathrm{L}$ pulp density and $1 \times 1 \mathrm{~cm}$ size.

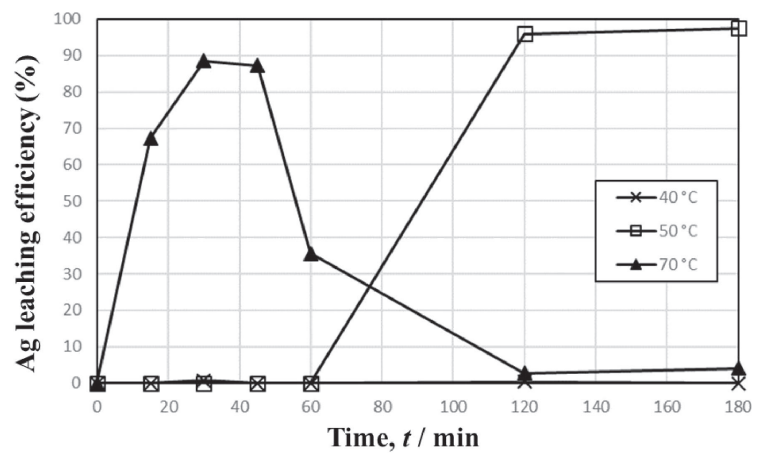

Fig. 8 The effect of temperature on the leaching efficiency of $\mathrm{Ag}$ in $1 \mathrm{M}$ nitric acid solution at $400 \mathrm{rpm}$ with $5 \%$ MEK addition, $10 \mathrm{~g} / \mathrm{L}$ pulp density and $1 \times 1 \mathrm{~cm}$ film size.

Figure 7 shows the leaching results carried out under the leaching conditions; $400 \mathrm{rpm}$ in agitation speed, $50^{\circ} \mathrm{C}$ in temperature, $10 \mathrm{~g} / \mathrm{L}$ in pulp density, $1 \times 1 \mathrm{~cm}$ in size, $1 \mathrm{M}$ in nitric concentration. The amount added of MEK was adjusted from $0 \%$ to $10 \%$. The leaching behavior of $\mathrm{Ag}$ in the leach solution with $2.5 \%$ MEK was not significantly different from that without addition of MEK. When 5\% MEK was added, the leaching efficiency of $\mathrm{Ag}$ increased up to $95.9 \%$ in $120 \mathrm{~min}$, but the leaching efficiency was about $4-11 \%$ in 180 min when added more than $7 \%$ of MEK. This methyl ethyl ketone is a partly miscible solvent with water, and the solubility in water is found to be $27.5 \mathrm{w} / \mathrm{v} \%$. This result indicates that the excess addition of MEK would reduce the oxidizing power of nitric acid in the solution due to dilution. Further study would be required to clarify the mechanism in detail.

The effects of temperature on the leaching of Ag were investigated in the $1 \mathrm{M}$ nitric acid solution with $5 \% \mathrm{MEK}$ at $50^{\circ} \mathrm{C}$ and $400 \mathrm{rpm}$ with $10 \mathrm{~g} / \mathrm{L}$ pulp density and $1 \times 1 \mathrm{~cm}$ size. As shown in Fig. 8, the leaching efficiency of Ag was almost close to zero at $40^{\circ} \mathrm{C}$ during whole leaching times, and any change was not observed in the X-ray film piece. The leaching efficiency at $50^{\circ} \mathrm{C}$ increased rapidly after $60 \mathrm{~min}$, and reach $95.9 \%$ at $120 \mathrm{~min}$. In the test at $70^{\circ} \mathrm{C}$, the leaching efficiency increased rapidly in the beginning of the leaching test and then decreased after $50 \mathrm{~min}$ to $2.7 \%$ at $120 \mathrm{~min}$. In the leach solution, some precipitate powders were observed and collected for further analysis. Only $\mathrm{Ag}$ and $\mathrm{Cl}$ were observed in XRF analysis, and this result indicates that the precipitate would be $\mathrm{AgCl}$. The X-ray film contains silver component as silver halide, and the silver halide is changed into elemental silver $\left(\mathrm{Ag}^{0}\right)$ by being exposed to light as the following equation; ${ }^{7)}$

$$
A g X=A g^{0}+X
$$

where $\mathrm{X}$ represents halide element such as $\mathrm{I}, \mathrm{Br}$, and $\mathrm{Cl}$. This free chloride would be liberated during the leaching test at $70^{\circ} \mathrm{C}$ and precipitate with $\mathrm{Ag}$ ion as $\mathrm{AgCl}$ due to extremely low solubility of $\mathrm{AgCl}{ }^{22}$ )

\section{Conclusion}

The use of MEK was investigated to enhance Ag recovery from the used X-fay film in the conventional nitric acid leaching processes. Two types of tests were carried out; nitric acid leaching of $\mathrm{Ag}$ after separating the emulsion layer from polyester film base using MEK, and adding MEK to nitric acid leaching of Ag from the used X-ray film.

The leaching efficiency of Ag from used X-ray film was enhanced by separating the emulsion layer from the polyester film base using MEK because the separation process increased the contact surface between nitric acid and silver in the emulsion layer. The separation efficiency increased with increasing temperature but decreasing pulp density and film size. Any significant effect was not observed in the agitation speed test. The feasibility of adding of MEK to nitric acid leaching was investigated. The addition of $5 \%$ MEK is most advantageous for recovering $\mathrm{Ag}$ from the used $\mathrm{X}$-ray film. When MEK was added to nitric acid leaching, the leaching efficiency of $\mathrm{Ag}$ increased at upto $50^{\circ} \mathrm{C}$ but further increasing to $70^{\circ} \mathrm{C}$ rather reduce the leaching efficiency due to the formation of $\mathrm{AgCl}$. These results indicate that silver could be recovered by using MEK at $1 \mathrm{M}$ nitric acid concentration. It is also possible to improve the conventional process by adding MEK to the nitric acid leaching process without new plant. Since the boiling points of MEK and nitric acid are $79.6^{\circ} \mathrm{C}$ and $83^{\circ} \mathrm{C}$, respectively, further study will be required to investigate the reuse of MEK and nitric acid employing a boiling process for economic and environmental efficiency.

\section{Acknowledgments}

This research was supported by the R\&D Center for Valuable Recycling (Global-Top R\&BD Program), Ministry of Environment, Republic of Korea (under the project no. 2016002250004).

\section{REFERENCES}

1) S. Syed: Waste Manag. 50 (2016) 234-256.

2) N. Nakiboglu, D. Toscali and G. Nisli: Turk. J. Chem. 27 (2003) 127133.

3) S. Shankar, S.V. More and R.S. Laxman: J. Sci. Eng. Technol. 6 (2010) 60-69.

4) O. Bondarenko, K. Juganson, A. Ivask, K. Kasemets, M. Mortimer and A. Kahru: Arch. Toxicol. 87 (2013) 1181-1200.

5) B. Reidy, A. Haase, A. Luch, K.A. Dawson and I. Lynch: Mater. 6 (2013) 2295-2350. 
6) J. Marinković, M. Korać, Ž. Kamberović and I. Matić: Acta Metall. Slovaca 12 (2006) 262-268.

7) A.D. Bas, E.Y. Yazici and H. Deveci: Hydrom. 121-124 (2012) 22-27.

8) N. Fujiwara, K. Yamamoto and A. Masui: J. Ferment. Bioeng. 72 (1991) 306-308.

9) R.M. Garcia: Hydrom. 16 (1986) 395-400.

10) V.I.E. Ajiwe and I.E. Anyadiegwu: Separ. Purif. Tech. 18 (2000) 8992.

11) P.A. Ramirez, V.E. Reyes and M.A. Veloz: Int. J. Electrochem. Sci. 6 (2011) 6151-6164.

12) E.Y. Yazici, A.D. Bas and H. Deveci: Proceedings of the XIIth International Mineral Processing Symposium, Cappadocia-Nevșehir, Turkey, 2010, pp. 741-748.

13) S. Syed, S. Suresha, L.M. Sharma and A.A. Syed: Hydrom. 63 (2002) 277-280.

14) S.O. Masebinu and E. Muzenda: Proceeding of the World Congress on Engineering and Computer Science, San Francisco, USA, 2014, pp. 22-24.

15) V. Choudhary: J. Acad. Indus. Res. 2 (2013) 39-41.

16) M. Tsunekawa, Y. Sasaki, Y. Nakamura, M. Ito, N. Hiroyoshi and K. Yoo: Mater. Trans. 49 (2008) 2119-2123.

17) S.H. Jeon, K. Yoo and R.D. Alorro: Hydrom. 169 (2017) 26-30.

18) G. Wypych: Handbook of Solvents, (ChemTec Publishing, Toronto, 2001) pp. 1028-1029.

19) S.A.E. Sadrnezhaad and M. Mozammel: J. Mater. Sci. Technol. 22 (2006) 696-700.

20) L.H. Le, K. Yoo, J. Jeong and J.-C. Lee: J. Korean Inst. Resources Recycling 17 (2008) 48-55.

21) K. Yoo, K. Lee, M.K. Jha, J.-C. Lee and K. Cho: J. Nanosci. Nanotechnol. 16 (2016) 11238-11241.

22) K. Yoo, J.-C. Lee, K.-S. Lee, B.-S. Kim, M.-S. Kim and S.-K. Kim: Mater. Trans. 53 (2012) 2175-2180. 